\title{
Theoretical foundations of the impact of documentation on urbanization and territory development
}

\author{
Kristina Merkuryeva ${ }^{1, *}$, and Alexander Kryakhtunov ${ }^{1}$ \\ ${ }^{1}$ Federal State Budget Educational Institution of Higher Education «Industrial University of \\ Tyumen», Lunacharskogo Street, 2, Tyumen, 6250016 Russia
}

\begin{abstract}
In an urban environment, the issue of the organization and development of spaces is particularly relevant and significant. The purpose of the study is to determine the role and importance of the preparation of urban planning and land management documentation in the process of development of the territory and urbanization. It is noted that the process of territorial development entails an increase in business, social, and, at the same time, construction activity. So, there is a need to improve infrastructure, development, reconstruction, as well as ensuring an acceptable ecological state of the environment. As a result of the analysis, the author concludes that in order to achieve significant results in the field of urban planning, the use of tools in the form of developed and approved urban planning and land management documentation is required, which will effectively organize the urban planning industry, thereby overcoming numerous and intractable social issues, and also contribute to raising quality of life.
\end{abstract}

\section{Introduction}

In connection with the increase in the territories of populated areas and urban spaces, the development of infrastructure, and the accelerated pace of development of urban planning and land management activities, a number of questions and problems arise that require research and finding ways to solve them. For many years, one of the leading roles in the activities of government bodies has been the process of regulating urban planning and land management activities. In order to improve and optimize the process of construction and planning, it is necessary to provide for a significant set of documents combining the legislative framework and traditional rules of urban planning. So, modernization processes spanning all spheres of life require immediate action to adopt the latest rules and norms, including standards for urban planning and land management. That is why, in the context of ongoing changes, there is a need for a fundamental study of the foundations of spatial development.

In modern conditions, it is not possible to successfully progress the process of urbanization and development of the territory without a detailed development, application

\footnotetext{
* Corresponding author: $\mathrm{k}$ r merkurieva@mail.ru
} 
and improvement of urban planning and land management documentation, which should be provided to all populated territories, without exception.

In addition, an important issue requiring attention and resolution is the establishment of a balance of interests between citizens and the state apparatus. It is important to provide for such norms and rules that would be able to meet safety requirements, provide a comfortable living environment for the population, as well as those capable of preserving the environment.

\section{Main part}

Town regulation in Russia has the status of an actively developing field of activity. As the market economy develops, the scale of such activity, the degree of awareness of its results and involvement in it inevitably grows, involving in the process of city regulation both managers of various levels and specialists of various profiles, as well as citizens who are not dedicated to special issues, but who have them business in everyday life.

Urban regulation should be understood as the process of regulation of urban development in accordance with the Urban Planning Code of the Russian Federation, carried out by authorities with the joint participation of citizens.«1» In turn, urban development is an activity to develop territories, including cities and other settlements, in the form:

1) territorial planning;

2) urban zoning;

3) layout of the territory;

4) architectural design;

5) construction, overhaul, reconstruction of capital construction facilities.

Today, when considering the problems of development of modern urban areas, the terms "urban planning" and "urbanization" are widely used.

Urban planning is a scientific and practical activity for the construction of urban and rural settlements and settlement systems. Urban planning considers the trends, principles and patterns of the formation of the settlement as a whole and its individual zones and systems.

Urbanization is a process of urban development, population concentration and urban life. Such a process has a socio-economic orientation of development, and is expressed in the growth of cities, the concentration of the population in them, especially in large cities, in the spread of urban lifestyle throughout the network of settlements. The modern period of social development is associated not only with the intensive growth of individual cities, but also with the formation of urban agglomerations and megacities. The rapid growths of urbanization and related problems have led to increased attention to finding ways to optimize urban development processes and improve living conditions in cities.

Any development process, including urban development, cannot proceed arbitrarily and uncontrollably; for its successful implementation, competent and consistent management is required. An important feature of such a process should be the relationship in the exercise of authority and the implementation of activities between federal planning and municipal administration of territories. In this connection, there is a need to establish, improve and consolidate the mechanism for the implementation of urban development, with the regulation of relevant processes, including the development, approval and implementation of documentation for the development of the territory, including urban planning and land management documents.

According to Article 19 of the Federal Law of June 18, 2001 No. 78-FZ "On Land Management", land management documentation should be referred to (Fig. 1). 


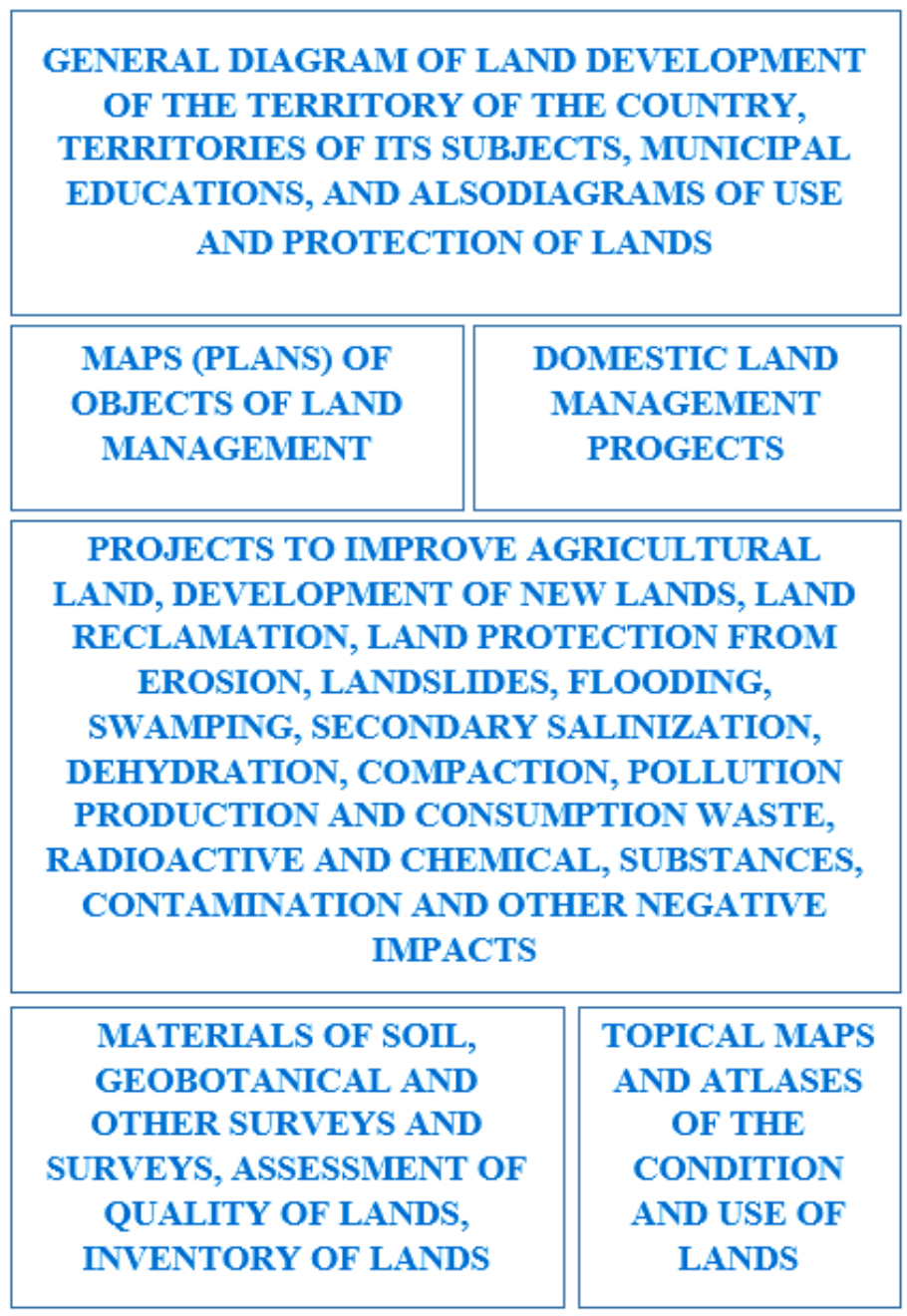

Fig. 1. Types of land management documentation.

Urban documentation should be understood as a documentation system that reflects the types and stages of design, ensuring the development and implementation of urban planning forecasts and programs, as well as the implementation of investments. «2» It include urban planning documentation (Fig. 2):

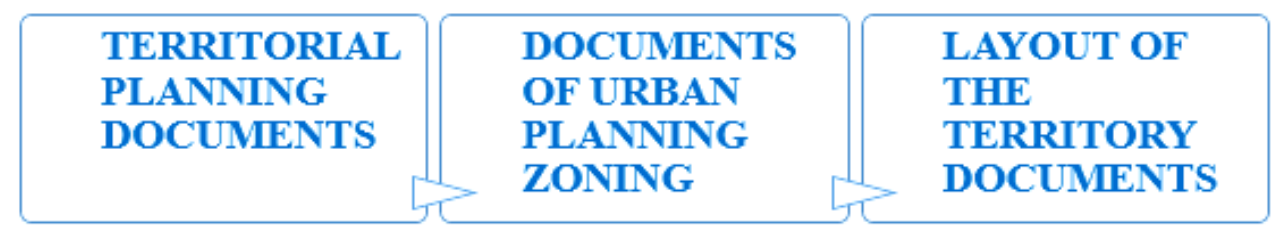

Fig. 2. Types of urban documentation.

The territorial planning documents include (Fig. 3): 


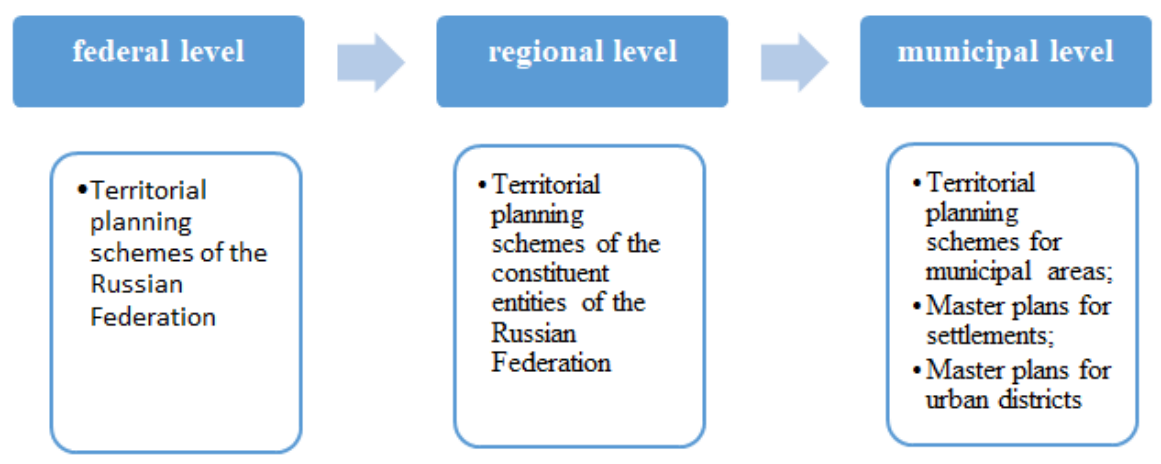

Fig. 3 Types of territorial planning documents.

The territorial planning documentation ensures the sustainable development of territories, as well as engineering, transport and social infrastructures, and takes into account the interests of citizens and their associations through the formation of social, economic and environmental factors.

The documents reflect the main activities necessary for the implementation of territorial planning, as well as the order and sequence of their implementation. It is important to note that the Territorial Planning Schemes and master plans do not contain direct and specific decisions on the use of territories, however, they are strategic documentation necessary for the development and approval of plans for the implementation of such documents. In addition, such documents serve as the basis for the formation of territory planning documents. The population, as well as business representatives, uses territorial planning documents to create a forecast for business development, build future plans, make choice of places of residence, recreation and employment.

So, the main purpose of territorial planning documents is to determine the direction and development path in various areas of life (for example, the approximate location and main characteristics of local objects - theaters, hospitals, schools, etc.). In the absence of such documents, it becomes impossible to make the right urban decision. In turn, an incorrect decision can lead to various kinds of consequences, and as a result, to a decrease in the quality of the living environment and people's activities.

In modern conditions of the existence of the real estate market, when the change of owners of real estate is a natural process, there is a need to establish the legal ownership of the use of the real estate and to fix the rules for its construction changes. In this case, the result and document of urban zoning are the rules of land use and development.

Land use and development rules contain (Fig. 4): 


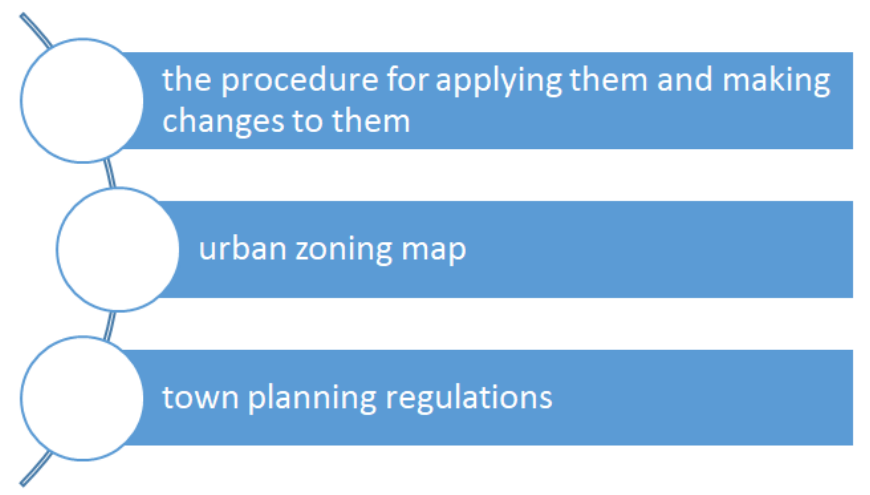

Fig. 4. The composition of the documents of urban zoning.

In order to highlight the elements of the planning structure (neighborhoods, microdistricts, etc.), to establish the boundaries of land under existing capital construction facilities or intended for the construction and placement of linear facilities, it is necessary to prepare documentation for the planning of the territory. So, ensuring sustainable development of the territory is impossible without developed and approved documents on the planning of the territory, the purpose of which, in contrast to the territorial planning documents, is more specific and understandable.

The documents for the planning of the territory include (Fig. 5):

\section{Territory planning project}

Fig. 5. Types of territory planning documentation.

When developing a territory planning project, the establishment of red lines, the formation of the boundaries of the zones of the planned placement of capital construction objects, as well as the determination of the development parameters of the territory are carried out. When developing a project for surveying the territory, the boundaries of undeveloped land plots planned to be provided to individuals and legal entities for construction, as well as the boundaries of land plots intended for placement of capital construction projects of federal, regional or local significance, are established.

Summing up, it should be noted that the development of all of the above documents is a multitasking and difficult process, since the success of the development of the territory depends on a combination of many factors that must be taken into account during the implementation of such a process.

Solving the problems of sustainable development of the territory and society is accompanied by an increase in the quality of life of citizens, which in turn forms the necessary maintenance of social stability. In the course of urban development activities, the spatial organization of the arrangement of the territory is improved, thereby improving the quality of the living environment of citizens, on which the quality of their life depends. «3»» The developments of land management and urban planning documentation, as well as the creation of information systems for supporting urban development activities, currently have a significant impact on the socio-economic development of territories. The development and completeness of the documentation affects the improvement of the business climate and the creation of a favorable living environment in the regions and municipalities. 
Today, the importance and necessity of urban planning and land management documentation of high quality is supported by the fact that its decisions, justified by implemented legal mechanisms and financial and economic calculations, ensure the promotion of territories in accordance with their strategic plans for socio-economic development.

Also, an important aspect is the quality of the land management and urban planning documentation being developed, which is evaluated in conjunction with the quality of management decisions made on its basis, and is also directly dependent on the assessment of the business climate, on the assessment of investment activity in the territory. So, the developed documentation should provide the opportunity to make the most effective decisions, the meaning of which is directly linked and based on the development directions defined by the strategies and the desired and attainable development indicators of these areas established by the standards of urban planning. «4» The effectiveness of the implementation of decisions and monitoring of their implementation is ensured through the introduction of technical requirements for the results of the developed documentation, the basis of which is the transition from a legal document to a legal entity through the creation and consistent development of spatial data infrastructure.

To ensure the successful implementation of the processes of development and application of urban planning and land management documentation, an extensive set of measures and actions should be implemented that can coordinate the process of urban regulation, which includes the proper implementation of urban development activities. A necessary condition for effective urban regulation is a comprehensive consideration of the totality of factors affecting the social, economic and environmental aspects of urban development. In this regard, a system of targeted actions that ensure the coordinated development of territories, public service systems and infrastructure should be understood as the management of urban development processes.

The management of urban development includes:

- development of urban planning policies that can determine the strategic and tactical goals of urban development and territorial development;

- ensuring conditions for achieving the goals in the long and short term;

- development of a normative and design model for the future state of the spatial organization of the territory;

- development of programs and plans for the implementation of the created models and their implementation;

- control over the actual distribution and efficiency of investments.

To manage the processes of urban development, information, technical, scientific, financial, staffing is created, forecasting and planning of development processes is conducted.«5» Making management decisions in urban planning is usually a compromise that takes into account different interests: state, public and private. To take into account all the interests in the field of urban development, it is necessary to fulfill the requirements of legal documents, urban development standards, implement land management and urban design documentation, as well as monitor their implementation. Only in this way will the goals be achieved to ensure favorable living conditions.

\section{Conclusion}

In conclusion, it should be said that the development of the territory is based on the solution of priority issues related to the effective urban development of the territories of regions and municipalities, ensuring the functioning of the economy in the field of land use, the formation of transport and social infrastructure, the development of housing and communal services, and the rationing of the construction of buildings and structures, as well as 
increasing the effective use of federal, regional and municipal property.«6» The solution of such issues and the result of such activities are reflected in land management and urban planning documents. In this connection, it can be concluded that the processes of urbanization and the development of territories are directly dependent on land management and urban planning documentation. Their direct influence is undeniable and unconditional.

Not a single process of urban planning and land management activity can be carried out without the development and application of relevant documentation. From which it follows that the processes of urbanization and development of territories in modern conditions are rapid and continuous. Their success directly depends on the quality and complexity of applying modern standards, as well as rational and practical management of current processes.

\section{References}

1. E. Trutnev, L. Bandorin, et al., Urban regulation: Fundamentals of regulation of urban development in the context of the real estate market, 13-16 (2008)

2. A. Beregovskih, Urban planning documentation 1, 18-19 (2008)

3. G. de Roo, D. Miller, Urban Environmental Planning. Policies, Instruments and Methods in an International Perspective, 128-136 (2016)

4. Institute of territorial planning "Grad», The decision of the conference "Urban planning and management, environmental quality and the business climate", 2-3 (2013)

5. G. Potaev, Trends of urban development, 11-19 (2014)

6. J. Carter, S. Jay, M. Shorts, C. Wood, Strategic Environmental Assessment and Land Use Planning an International Evaluation, 6-12 (2006) 